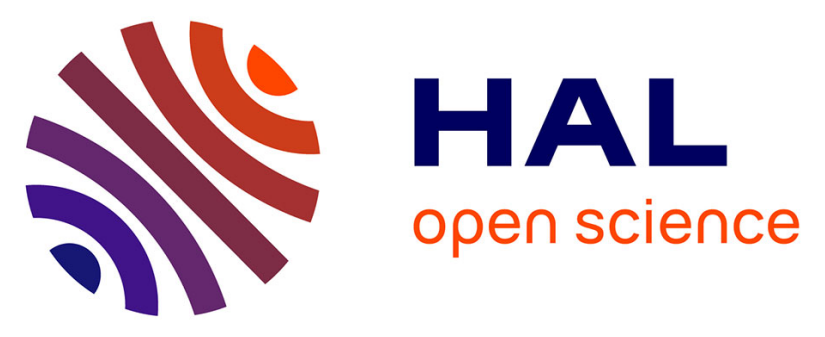

\title{
Pre-participation cardiovascular evaluation in Pacific Island athletes
}

\author{
Jean-Claude Chatard, Florian Espinosa, Richard Donnadieu, Jean-Paul \\ Grangeon, Jean-Marie Sabot, Christian Guivarch, Régis Dacquin, \\ François-Xavier Raby, Gérard Papouin, Satu Viali, et al.
}

\section{To cite this version:}

Jean-Claude Chatard, Florian Espinosa, Richard Donnadieu, Jean-Paul Grangeon, Jean-Marie Sabot, et al.. Pre-participation cardiovascular evaluation in Pacific Island athletes. International Journal of Cardiology, 2019, 278, pp.273-279. 10.1016/j.ijcard.2018.11.012 . hal-01987936

\section{HAL Id: hal-01987936 \\ https://hal-univ-rennes1.archives-ouvertes.fr/hal-01987936}

Submitted on 24 Jan 2019

HAL is a multi-disciplinary open access archive for the deposit and dissemination of scientific research documents, whether they are published or not. The documents may come from teaching and research institutions in France or abroad, or from public or private research centers.
L'archive ouverte pluridisciplinaire HAL, est destinée au dépôt et à la diffusion de documents scientifiques de niveau recherche, publiés ou non, émanant des établissements d'enseignement et de recherche français ou étrangers, des laboratoires publics ou privés. 


\section{Pre-participation cardiovascular evaluation in Pacific Island athletes}

Jean-Claude Chatard $^{\mathrm{a}^{*}}$, Florian Espinosa ${ }^{\mathrm{b}}$, Richard Donnadieu ${ }^{\mathrm{c}}$, Jean-Paul Grangeon ${ }^{\mathrm{d}}$, Jean-Marie Sabot ${ }^{\mathrm{c}}$, Christian Guivarch ${ }^{\mathrm{e}}$, Régis Dacquin ${ }^{\mathrm{e}}$, François-Xavier Raby ${ }^{\mathrm{f}}$, Gérard Papouin $^{\mathrm{f}}$, Satu Viali ${ }^{\mathrm{g}}$, Corinne Braunstein ${ }^{\mathrm{h}}$, Antoine Gerbay ${ }^{\mathrm{b}}$, Frédéric Roche ${ }^{\mathrm{i}}$, Karl Isaaz ${ }^{\mathrm{b}}$, Jean-Claude Barthélémy ${ }^{\mathrm{i}}$, and François Carré

a - Inter-university Laboratory of Human Movement Science, Faculty of Medicine Jacques Lisfranc, University Lyon-Saint-Etienne, 42023 Saint-Etienne, France

${ }^{\mathrm{b}}$ - Department of Cardiology, Faculty of Medicine Jacques Lisfranc, University LyonSaint-Etienne, 42023 Saint-Etienne, France

${ }^{c}$ - Sports Medical Centre of Noumea, New-Caledonia,

d - Direction of the Health and Social Affairs, Noumea, New-Caledonia

e - Sports Medical Centre of Tahiti, French Polynesia

f - Department of cardiology, Taone Hospital, Tahiti, French Polynesia

g - Department of cardiology, Apia Hospital, Samoa

h - Department of cardiology, Gaston Bourret Hospital, Noumea, New-Caledonia

i - Laboratory of Autonomous Nervous System, Faculty of Medicine Jacques Lisfranc, University Lyon-Saint-Etienne, 42023 Saint-Etienne, France

j - CHU Pontchaillou, University of Rennes 1, INSERM U1099 France

\section{*Corresponding author :}

Jean-Claude Chatard

Service de Physiologie Clinique et de l'Exercice 
CHU de Saint-Etienne

42055 Saint-Etienne cedex 2

Tel: +33477127234

E-mail: chatard@univ-st-etienne.fr

Running Heading: Screening Pacific Island athletes

Word Count: abstract 245 words, text 3436 words 


\section{Abstract}

Background: Pre-participation cardiovascular evaluation (PPE) aims to detect cardiac disease with sudden cardiac death (SCD) risk. No study has focused on Pacific Island athletes.

Methods: A total of 2281 Pacific Island athletes were studied with (i) a questionnaire on family, personal history and symptoms, (ii) a physical examination and (iii) a 12-lead ECG.

Results: $85 \%$ presented a normal history and examination. A positive family history was 1.4-1.9 fold higher in Melanesians, Polynesians and Métis than in Caucasians, while a positive personal history, abnormal symptoms and abnormal examination was 1.3 fold higher in Melanesians and Métis than in others. Neither gender nor training level had a bearing on these results. Melanesians had higher T wave inversions (TWIs) in V2-V4 leads but had no CV abnormalities. Lateral or infero-lateral TWIs were found in 6 male and in 5 highly trained athletes and cardiomyopathies were diagnosed in 3/6 athletes. Overall, 3.9\% athletes were found to have a CV abnormality and $0.8 \%$ had a risk of SCD. Polynesians and males were more at risk than the others while the level of training made no difference. In athletes at risk of $\mathrm{SCD}$, the main detected $\mathrm{CV}$ diseases were cardiomyopathies, Wolff-Parkinson-White (WPW) and severe valve lesions of rheumatoid origin.

Conclusions: PPE revealed that 3.9\% presented CV abnormalities. A risk of SCD was found in $0.8 \%$ with cardiomyopathies, WPW, and severe valve lesions of rheumatoid 
origin. Melanesians, Polynesians and male of high level of training were more at risk than others.

Keywords: Pre-participation cardiovascular evaluation; Cardiomyopathy; Sudden cardiac death; T wave inversion; Melanesians; Polynesians 


\section{1 - Introduction}

Sport provides health benefits, but sudden cardiac death (SCD) can reveal hitherto undetected cardiovascular (CV) disease. The estimated incidence rate of SCD is 1-2/100 000 athletes/year [1] and can be as high as 1/17 000 or 1/3 300 in some specific sports and ethnicities like Afro-Caribbean basketball players [2]. The proposition of a preparticipation cardiovascular evaluation (PPE) is presented as justifiable on medical grounds [3] with the aim to detect a CV disease and/or a disease with SCD risk. As about $80 \%$ of these diseases are asymptomatic, a resting 12-lead electrocardiogram (ECG) although controversial [4], is recommended as a valid, cost effective means of athlete screening [5].

Athlete's ethnicity has a significant impact on the CV response to a high level of physical training as on the SCD risk. In comparison with Caucasians, heart specificities have been reported in Afro-Caribbean [6, 7], Asian [8] or West-Asian athletes [9]. Moreover, it has been reported that Afro-Caribbean athletes are more susceptible to SCD than Caucasians [10]. No study has focused on Pacific Island athletes.

The aim of this study was to present the results of a PPE carried out on 2281 Pacific

Island athletes. A second aim was to specify the differences related to the ethnicity of Melanesians, Polynesians, Caucasians and Métis, to their gender and to their level of training.

\section{2 - Methods}


The study design was approved from the University and Sports Medicine Hospital ethics committee of Saint-Etienne.

\section{1 - Population}

From 2012 to 2015, 2281 athletes, 716 females, were studied and written informed consent. They were regularly involved in competition and registered in 40 sports federations. Football (392), volley ball (303), martial arts (286) and rugby (213) accounted for $52 \%$ of the athletes. They were also involved in 2 Pacific-specific sports Va'a, namely, sea canoe, (119) and sailing (93).

\section{Ethnicity}

Athletes were recruited from 14 Pacific Islands: New Caledonia (1 450), French Polynesia (489), Fiji (108), Wallis and Futuna (69), Tonga (38), Tuvalu (36), Vanuatu (31), Papua New Guinea (28), 2 Samoas (15), Cook, Salomon and Palau islands (17).

Attention was focused on Melanesians ( $n=702,278$ females), Polynesians ( $n=653$, 165 females), Caucasians $(\mathrm{n}=469,138$ females $)$ and Métis $(\mathrm{n}=457,135$ females). Almost all of them, including Caucasians were native to these Pacific Islands. The term "Métis" was used when at least one parent or one of the 4 grand-parents was not from the same ethnicity as the others.

\section{Level of training}

Athletes were divided into two groups, those training more than $6 \mathrm{~h} /$ week $(\mathrm{HT}, \mathrm{n}=$ 1336,363 females) and those training less than $6 \mathrm{~h} /$ week (LT, $\mathrm{n}=945,353$ females).

\section{2 - Pre-participation cardiovascular evaluation}


All athletes underwent the same PPE that included family and personal history, a physical examination and a 12-lead resting ECG. When athletes had several PPEs, only the first PPE was recorded. In New Caledonia and French Polynesia, as in France, the PPE is routinely performed. Concerning the other Islands, the PPE was performed as a part of the research project during the 2013 Mini Pacific Games in Wallis.

History and physical examination.

All athletes completed a questionnaire including the main items from the AHA 12elements [11]. The medical history addressed present and past complaints as well as family history [12].

The physical examination was based on the Consensus Statement from the European Society of Cardiology sports group $[13,14]$.

Resting 12-Lead Electrocardiography (ECG)

After resting for 5-10 min, in the supine position, a 12-Lead ECG (Mac 1 200, GE, USA or Nihon Kohden, Japan) was recorded. The ECG analysis was initially carried out using The Seattle criteria [15]. At the end of the study, they were reviewed using the international classification proposed in 2017 [3].

\section{Further evaluation}

All athletes presenting abnormal findings were offered further complementary cardiac screening. As the burden of rheumatoid heart disease (RHD) is significant in the Pacific region, echocardiography was systematically offered to athletes with a family and/or personal history of Acute Rheumatic Fever (ARF) and/or who presented with a heart murmur at the physical examination. The WHF 2012 criteria [16] were applied. 
Athletes with normal history and physical examination and with normal ECG did not undergo any other investigation.

It must be pointed out that in some low-income Pacific Islands some investigations, although highly recommended, like transthoracic echocardiography (TTE), 24h Holter recording, stress ECG, Magnetic Resonance Imaging (MRI), could not always be performed either for economic reasons, or the lack of sports cardiologists or specialized medical facilities.

\section{3 - Statistical analysis}

Multivariate Anova Analysis and one-way Anova analysis were carried out between ECG criteria, age, ethnicity, gender, and training level. A Fisher and Scheffe post hoc procedure was used to determine the location of the differences. A $P$ value of 0.05 was chosen as the level of statistical significance. The Stata 11 program was used for the statistical analysis.

\section{3 - Results}

\section{1 - Athletes' demographics}

The 2281 athletes were on average $19.4 \pm 6.5$ years old (age range 10-40) and trained $8.6 \pm 5.0 \mathrm{~h} /$ week (Table 1 and 2). Male Polynesians were significantly older, taller, and heavier than the other ethnic groups $(P<0.05)$. Regarding female athletes, Melanesians were younger and smaller than Polynesians and Métis and trained less than Polynesians 
$(P<0.05)$, while female LT athletes were younger and smaller than female HT athletes $(P<0.05)$.

\section{2 - History and physical examination}

$85.4 \%$ of all athletes presented a normal history and physical examination, whereas $14.6 \%$ presented an abnormal history and/or physical examination (Figure 1).

The family history was positive for at least one item in $6.8 \%$ of athletes. The most frequent item was death of $\mathrm{CV}$ origin $(n=52,1.3 \%)$, father $\mathrm{n}=28$, mother $\mathrm{n}=17$, brothers and sisters $(\mathrm{n}=5)$ with $31(0.8 \%)$ of family members younger than the age of 50. Other items were coronary artery diseases, valvular diseases, aneurysms, inter atrial or ventricular communications, pace-makers, hypertrophic cardiomyopathy, arrhythmias and high blood pressure.

The incidence of a positive family history was $1.4-1.9$ fold higher $(P<0.05)$ in Melanesians (6.3\%), Polynesians (8.6\%) and Métis (7.2\%) when compared to Caucasians (4.5\%). There was no statistical difference between males and females or between LT and HT athletes.

The personal history was positive in at least 1 item in $3.2 \%$ athletes and $2.0 \%$ athletes complained about at least 1 abnormal symptom during exercise. The most frequent item was RHD history $(\mathrm{n}=47)$ followed by abnormal dyspnea $(\mathrm{n}=23)$, while the most frequent symptoms were palpitations $(\mathrm{n}=13)$, syncope or near syncope $(\mathrm{n}=8)$ and thoracic pain $(\mathrm{n}=7)$.

The physical examination was abnormal in $4.2 \%$ of athletes including 91 cardiac murmurs and 6 high blood pressure values. 
The incidence of a positive personal history, abnormal symptom and abnormal examination was 1.3 fold higher $(P<0.05)$ in Melanesians $(9.8 \%)$ and Métis $(12.9 \%)$ when compared to Polynesians (6.3\%) and Caucasians $(8.5 \%)$. Gender did not have an impact on these findings nor did the level of training.

\section{3 - ECG analysis}

Most of the ECG variables were independently related to age, ethnicity, gender and duration of training.

In the total population, heart rate (HR) was $<40 \mathrm{bpm}$ in $10(0.4 \%)$ athletes and $<50$ bpm in $140(6.1 \%)$ athletes. No HR lower than 30 bpm was observed.

Electrical left atrial enlargement (LAE) and right atrial enlargement (RAE) were observed respectively in $2.2 \%$ and $0.6 \%$ athletes. They did not reveal any abnormalities.

Atrio ventricular block (AVB) type 1 was observed in $2.5 \%$ and a PR interval duration of $\geq 220 \mathrm{~ms}$ in $0.9 \%$ and $\geq 300 \mathrm{~ms}$ in $0.2 \%$ athletes. No PR duration longer than $400 \mathrm{~ms}$ was observed. A PR interval duration $<120 \mathrm{~ms}$ with pre-excitation was found in 6 athletes $(0.3 \%)$.

Isolated complete right bundle branch block (RBBB) was observed in only 1 athlete. Isolated QRS duration > 140 ms was found in 9 athletes $(0.4 \%)$. Isolated QRS complex axis deviation $>120^{\circ}$ was found in $7(0.3 \%)$ male athletes and $<-30^{\circ}$ in $5(0.2 \%)$ athletes (4 males and 1 female). Isolated electrical left ventricular hypertrophy, (LVH), SokolowLyon index, was found in $14 \%$ of athletes, Melanesians (10.7\%), Polynesians (15.3\%), Caucasians (18.1\%) and Métis (12.9\%). Isolated electrical right ventricular hypertrophy 
(RVH) was found in $7.4 \%$ athletes, Melanesians (4.3\%), Polynesians (12.1\%), Caucasians (6.4\%) and Métis (6.3\%).

Q waves steeper than $3 \mathrm{~mm}$ were found in $0.4 \%$ athletes, 9 males and 1 female. Of these athletes, only 1 had a $\mathrm{Q} / \mathrm{R}$ ratio $>25 \%$, none had a $\mathrm{Q}$ wave duration > $40 \mathrm{~ms}$. They did not reveal any abnormalities.

$\mathrm{T}$ wave inversions (TWIs) were observed in 45 athletes $(2.0 \%)$. TWIs concerned V2V4 leads in 39 athletes, 27 (69\%) were $\leq 16$ years old. The incidence was 1.4-2.0 fold higher $(P<0.05)$ in Melanesians $(2.6 \%)$ than in Polynesians $(1.2 \%)$, Caucasians $(1.5 \%)$ and Métis $(1.3 \%)$. In most cases $(31 / 39=79 \%)$, TWIs were associated with a $\mathrm{J}$ point elevation with convex ST segment with a 2-fold higher incidence in Melanesians $(2.1 \%)$ than in Polynesians (1.1\%), Caucasians (0.9\%) and Métis $(1.1 \%)$.

Lateral or infero-lateral TWIs were found in 6 athletes, 3 Melanesians, 1 Caucasian and 2 Métis. They were all males and 5 were HT athletes. HCM was diagnosed in the only 3 athletes that could be further investigated.

The QTc interval duration was on average $10 \mathrm{~ms}$ longer in females than in males. Four athletes presented a prolonged QTc duration between 470 and $510 \mathrm{~ms}, 2$ males, 2 females, 2 Polynesians, 1 Melanesian and 1 Métis.

More than 2 premature ventricular beats were observed in 6 athletes, 4 Polynesians, 1 Melanesian and 1 Métis, 4 males and 2 females, 5 HT and 1 LT athlete. Supra ventricular tachycardia was observed in only 1 male HT Polynesian.

\section{4 - Results of the pre-participation evaluation}

The results of the PPE are summarized in Figure 1 and Table 3. 
History and physical examination abnormalities concerned $14.6 \%$ athletes of which $1.6 \%$ presented abnormalities in both their history and examination. Of these athletes, an associated abnormal ECG was observed in 45 (2.0\%). In these 45 athletes, $7 \%$ had a positive family history, $42 \%$ a positive personal history, $22 \%$ were symptomatic and $56 \%$ had an abnormal physical examination.

Isolated abnormal ECG results concerned $1 \%$ athletes.

Athletes with an abnormal ECG, and/or abnormal history, symptoms and physical examination were invited to undergo complementary CV evaluations: 71 underwent all the CV evaluations. Very few athletes refused to undergo further investigation. However in the case of some low-income athletes/islands, for economic reasons, 17 did not undergo either the TTE $(n=5)$ or the MRI scan $(n=12)$. Overall 88 athletes $(3.9 \%)$ presented a CV abnormality.

A group of 21 athletes presented both abnormal examination and normal ECG. In 18, the CV abnormalities were diagnosed by echocardiography. In the 21 athletes, 14 RHDs had an abnormal personal history $(n=11)$ and or heart murmur $(n=6): 4$ inter auricular or ventricular communication had a heart murmur: 3 cases of high blood pressure an abnormal examination.

The incidence of $\mathrm{CV}$ abnormalities was 1.4 fold higher $(P<0.05)$ in Polynesians (5.1\%), when compared to Melanesians (3.4\%), Caucasians (3.4\%), or Métis (3.3\%). The incidence was higher $(P<0.05)$ in males $(4.2 \%)$ than in females $(3.1 \%)$ but was almost the same between LT and HT athletes (3.8\% as opposed to $3.9 \%$ ).

Globally a CV disease associated with a potential risk of SCD was identified in 18 (0.8\%) athletes. Familial and personal history was abnormal in 5 athletes, personal 
history in 7, abnormal symptom in 6: syncope $(n=4)$, palpitations $(n=1)$ and thoracic pain (n=1). Lastly the disease was detected by isolated abnormal ECG in 6 athletes.

The incidence was 2 to 6 -fold higher $(\mathrm{P}<0.05)$ in Polynesians $(1.7 \%)$ than in Melanesians $(0.6 \%)$, Caucasians $(0.2 \%)$ or Métis $(0.4 \%), 3$-fold higher in males than in females $(1.1 \%$ vs. $0.3 \%, P<0.01)$ and 4 -fold higher in HT than in LT athletes $(1.1 \%$ vs. $0.3 \% P<0.01)$. There were $6(0.3 \%)$ cardiomyopathies detected in 3 Polynesians, 2 Melanesians and 1 Métis that included 4 HCMs, 1 left and 1 right uncompacted ventricle, all had abnormal ECGs, however, only $3 / 6$ were symptomatic; 6 cases $(0.3 \%)$ of WolffParkinson-White in 4 Polynesians and 2 Melanesians; 5 severe valve lesions $(0.2 \%)$, in 3 Polynesians, 1 Caucasian and 1 long QT syndrome (LQT1 type) in a Polynesian.

Fifty-three other CV diseases not linked to a risk of SCD were identified. They included 30 low grade valve diseases, 8 mild inter-auricular or ventricular communications, 8 low-risk arrhythmias, 6 cases of high blood pressure, and 1 low-risk coronary artery malformation. The incidence was $1.3-1.4$ fold higher $(P<0.05)$ in Melanesians and Caucasians (2.3\%-2.8\%) than in Polynesians and Métis (2.1\%-2.0\%). In the severe or low grade valve diseases, a rheumatoid origin was identified in $60 \%$ athletes.

Other abnormal ECGs $(\mathrm{n}=17)$ included 10 abnormal TWIs that could not be investigated by an MRI scan for economic reasons; 4 prolonged QTc, 2 were considered as normal after an expert opinion and 2 could not be investigated further. The 3/17 last abnormal ECGs were 1 abnormal Q wave and 2 abnormal QRS in right leads associated 
with axis deviation, complete RBBB and RVH. No right cardiomyopathy was confirmed by complementary examination. Regular monitoring was recommended.

\section{4 - 2012-2017, follow-up}

A 5-year follow up could be carried out only on the 1450 New Caledonian studied. Indeed PPE was not regularly organized in the 13 other Pacific Islands. Despite the PPE, 3 athletes died of a SCD. The first one was an 18 year old male Melanesian football player diagnosed with HCM. Although medically advised against participation in intensive sports, he continued to play and died during a football match. The second was a female Polynesian who died at rest. ECG and echocardiography carried out previously were normal. The diagnosis of prolonged QT was suspected because her untrained sister presented a prolonged QTc > $480 \mathrm{~ms}$. Neither an autopsy nor a genetic test could be carried out. The third athlete was a Caucasian male triathlete with normal ECG and echocardiography. He died during a swimming session. The autopsy, without genetic or toxicology tests, was concluded as negative. In first-degree relatives, ECG, echocardiography and 24h Holter ECG recordings were normal. PPE could not prevent 2 if not 3 SCDs in 5 years in 1450 athletes per year. It corresponded to 1 SCD per 2416 or 3625 athletes/year.

\section{4 - Discussion}


The first aim of this study was to present the results of a PPE carried out on 2281 athletes from Pacific Islands. The PPE performed was fully normal for more than $85 \%$. This value is close to the $90 \%$ found by Fuller et al. in 5615 high school athletes [17].

In the $15 \%$ athletes that had to undergo further investigations, $3.9 \% \mathrm{CV}$ abnormalities were found. They included $3.1 \%$ proven $\mathrm{CV}$ diseases and $0.7 \%$ suspected $\mathrm{CV}$ diseases as the CV investigations could not be carried out fully.

CV diseases linked to a risk of SCD were limited to $0.8 \%$ athletes.

The second aim of the study was to identify ECG pattern related to ethnicity, gender and training level. Melanesian athletes presented with frequent TWIs in V2-V4 similar to those described in Afro-Caribbean athletes. Most of infero-lateral TWIs were associated with cardiomyopathies. ECG findings were different between males and females and between low and high level trained athletes confirming that the 2017 international recommendations [3] are applicable for Pacific Island athletes.

\section{1 - History and physical examination}

Positive family, personal history, symptoms and physical examination were present in $14.6 \%$ of the athletes. Of them, only $20 \%$ presented with a proven or suspected cardiac disease. From these data, it must not be concluded that history and physical examination are of minor importance in athletes' PPE. Indeed, in the $3.9 \%$ athletes having a cardiac abnormality, $50 \%$ athletes had one or more positive item. These data are in contrast with previous studies showing that history and physical examination led to an accurate diagnosis in only 1 to $3 \%$ of athletes $[18,19]$. Effectiveness to detect diseases is debated 
as many cardiovascular diseases remain silent and difficult to diagnose as some warning symptoms may be misinterpreted by medical providers [20].

These data confirm that history and physical examination remain of major importance in athletes' PPE [21].

\section{2 - ECG analysis}

Of the 13 studied ECG criteria, 9 were related to ethnicity, 13 to gender and 9 to the training level.

Early repolarization concerned around $50 \%$ of athletes. This ECG pattern that has classically been viewed as benign [14] confirmed previous studies concerning AfroCaribbean athletes [22].

Melanesians presented more frequent abnormal TWIs than other ethnicities. Most of TWIs were found in athletes under the age of 16 and TWIs were located in V2 to V4 leads confirming previous observations in young Caucasians [23]. They were often associated with a J point elevation and a domed ST segment. As none of them presented any CV disease, they were considered as early repolarization as in the case of AfroCaribbean athletes [3].

The relationship observed between ECG criteria and training level confirms that the classifications $[15,19,24]$ proposed for the interpretation of athletes' ECG and especially the 2017 international recommendations [3] are applicable for Pacific Island athletes.

\section{3 - Results of the pre-participation evaluation}


Out of the athletes, $3.9 \%$ presented with a $\mathrm{CV}$ disease that needed a regular medical follow-up, $0.8 \%$ were identified with a cardiac disease associated with a potential risk of SCD. These values are close to those reported in a review of 12 studies grouping 55396 athletes [1].

Athletes with SCD risk were contraindicated to competition, training being allowed only at a low intensity. Unfortunately, not of all them followed these recommendations as at least one died during a football match. For WPW, athletes were allowed to train and to compete again after successful ablation treatment.

The 2.6/1 000 athlete prevalence of HCM found in the present study is also close to the prevalence found by Wilson et al. [9] i.e. 3.2/1 000 in West Asian Athletes. In these 2 studies, Afro-Caribbeans or Melanesians were highly present $31 \%$ as opposed to $25 \%$.

This data highlights that cardiomyopathies concerns in the same way Melanesians and Polynesians. Only 50\% were symptomatic, while all had an abnormal ECG confirming the value of this exam $[3,5,25]$.

Specific attention was given to the 45 athletes with deep TWIs. In this population, 4 HCMs were diagnosed. However, because of economic reasons, all athletes did not undergo echocardiography and cardiac MRI. Thus, the diagnosis of cardiomyopathy was probably underestimated as MRI alone increases by $35 \%$ the diagnosis of HCM in athletes with ITWs and a normal echocardiography [26].

In the present study, the incidence of WPW was high and close to the total incidence of the cardiomyopathies, confirming previous screening studies $[1,7]$.

A major observation resulting from this study was the high prevalence $(1.5 \%)$ of valvular diseases of rheumatoid origin. The prevalence was 3.9 fold higher than those 
reported in athletes of Western and Middle East countries [1], confirming that RHD remains highly prevalent in the Pacific region $[27,28]$.

\section{4 - Incidence rate of sudden cardiac death.}

An estimate of the efficacy of the PPE was somewhat difficult. Indeed, 18 athletes were identified with a cardiac disease associated with a potential risk of SCD. Clearly, PPE could not detect nor prevent 2 SCDs in the New Caledonian population confirming previous observation in athletes $[17,29,30]$. In the present study, the observed SCD rate was very high when compared with previous ones. However, strength of the study was the sources of data that were reliable. Indeed, New Caledonia is a small country easy to survey. It is also pointed out that these values were close to values

\section{found by Harmon et al. [31] in black African-American basketball players.}

\section{5 - Limitations of the study}

A major limitation of this study was the lack of control groups. However, it seemed very hard to recruit a large group of healthy volunteers from the populations studied. As we compared data observed in LT and HT levels athletes, it was thought that the LT level subjects could be considered close to the 2-3 h/week average of school, college or adult untrained people.

As emphasised above, a detailed and exhaustive CV evaluation deemed necessary after the initial examination could not be carried out because of economic reasons and/or lack of medical staff and facilities.

\section{5 - Conclusion}


This study gives for new information concerning family and personal history, symptoms, physical examination, ECG findings and cardiovascular abnormalities detected after a PPE in a large population of Pacific Island athletes.

A normal PPE was recorded for $85 \%$ of athletes. ECG findings were different between males and females and between low and high level trained athletes confirming that the 2017 international recommendations [3] are applicable for Pacific Island athletes.

Melanesians presented with frequent TWIs in V2-V4 similar to those described in Afro-Caribbean athletes. Most of other TWIs were associated with cardiomyopathies.

Overall, 3.9\% of athletes presented a CV disease requiring an annual CV follow-up and $0.8 \%$ athletes were disqualified from competitive sport due to the risk of SCD. A high prevalence of RHD $1.5 \%$ was found. All these data confirm the importance of a PPE including ECG for Pacific Island athletes.

\section{Acknowledgments}

The authors would like to thank Mr. James Pryce who has extensive experience revising medical articles for reviewing the English manuscript.

Authors also want to thank for their major help:

Drs Eric Beaumond, Pierre Bourgoin, François Cade, Philippe Costes, Christian Decanlers, Robert Daughty, Fleur Decoutures, Rachid El Belghiti, Francis Etienne, Fleur Découtures, Michel Galtier, David Gerrard, Philippe Guérin, Olivier Guillemin, Michel Herody, Bertrand Huon, Joel Kamblock, Michel Lafuente, Anael Lameyse, Sylvie 
Laumond, Gérard Lefèbre, Damien Lejeune, Eric Mahieu, Jean-Michel Meunier, Mariana Mirabelle, Isabelle Nécib, Baptiste Noël, Bruno Pagis, Jean-Marie Papillo, Bertrand Pouget, Claude Robin, Jean-Marc Ségalin, Vincent Simon, In Sirivuth, Emmanuel Tarpinian, Franck Terdiman, Didier Thiriot, Bruno Ulmer and Cengiz Yildiz.

Mr. or Mrs. Anne Basili, Dominique Baugy, Jean-Pierre Bellon, Franck Boivert, Jenny Bousquet, Magali Carret, Pierre Forest, Marcel Guiomard, Danièle Guyonnet, Doris Hart, Anne-Marie and Thierry Jutel, Jennifer Khalik, Mae Lhopital, Catherine Millot, HenriPierre Nallet, Rafael Pont, Philippe Saint-Val, Eric and Isabelle Zorgnoti, Marleen Van Roosmalen and Laure Yen Kai Sun.

\section{Contributors}

JCC had full access to all data in the study and takes responsibility for the integrity of the data and the accuracy of the data analysis. JCC, FE, JCB and FC had the idea for and designed the study. All authors had a substantial contribution to the conception and design and to the collection of the data. JCC and FE provided statistical analysis. JCC, FE, AG, FR, KI, FC were responsible for interpretation of the data. JCC, FE and FC drafted the manuscript and submitted the paper for publication. All authors approved the final version.

\section{Findings}


This work was supported by a grant from Fond Pacific and the Ministère des Affaires

Etrangères et du Développement international, AFD CTZ $105601 \mathrm{~T}$ and a grant from Philips industry.

Authors have no conflict of interest to declare. 


\section{References}

[1] J.C. Chatard, I. Mujika, J.J. Goiriena, et al., Screening young athletes for prevention of sudden cardiac death: Practical recommendations for sports physicians, Scand J Med Sci Sports, 26 (2016) 362-374.

[2] K.G. Harmon, M. Zigman, J.A. Drezner, The effectiveness of screening history, physical exam, and ECG to detect potentially lethal cardiac disorders in athletes: a systematic review/meta-analysis, J Electrocardiol, 48 (2015) 329-338.

[3] S. Sharma, J.A. Drezner, A. Baggish, et al., International Recommendations for Electrocardiographic Interpretation in Athletes, J Am Coll Cardiol, 69 (2017) 1057-1075.

[4] B.J. Maron, T.S. Haas, C.J. Murphy, et al., Incidence and causes of sudden death in U.S. college athletes, J Am Coll Cardiol, 63 (2014) 1636-1643.

[5] K. Prakash, S. Sharma, The Electrocardiogram in Highly Trained Athletes, Clin Sports Med, 34 (2015) 419-431.

[6] S. Basavarajaiah, A. Boraita, G. Whyte, et al., Ethnic differences in left ventricular remodeling in highly-trained athletes relevance to differentiating physiologic left ventricular hypertrophy from hypertrophic cardiomyopathy, J Am Coll Cardiol, 51 (2008) 2256-2262.

[7] N. Sheikh, M. Papadakis, S. Ghani, et al., Comparison of electrocardiographic criteria for the detection of cardiac abnormalities in elite black and white athletes, Circulation, 129 (2014) 1637-1649.

[8] G. Kervio, A. Pelliccia, J. Nagashima, et al., Alterations in echocardiographic and electrocardiographic features in Japanese professional soccer players: comparison to African-Caucasian ethnicities, Eur J Prev Cardiol, 20 (2013) 880-888.

[9] M.G. Wilson, J.C. Chatard, F. Carre, et al., Prevalence of electrocardiographic abnormalities in West-Asian and African male athletes, Br J Sports Med, 46 (2012) 341347.

[10] K.G. Harmon, I.M. Asif, J.J. Maleszewski, et al., Incidence, Cause, and Comparative Frequency of Sudden Cardiac Death in National Collegiate Athletic Association Athletes: A Decade in Review, Circulation, 132 (2015) 10-19.

[11] B.J. Maron, B.D. Levine, R.L. Washington, et al., Eligibility and Disqualification Recommendations for Competitive Athletes With Cardiovascular Abnormalities: Task Force 2: Preparticipation Screening for Cardiovascular Disease in Competitive Athletes: A Scientific Statement From the American Heart Association and American College of Cardiology, J Am Coll Cardiol, 66 (2015) 2356-2361.

[12] K. Bille, D. Figueiras, P. Schamasch, et al., Sudden cardiac death in athletes: the Lausanne Recommendations, Eur J Cardiovasc Prev Rehabil, 13 (2006) 859-875.

[13] D. Corrado, A. Pelliccia, H.H. Bjornstad, et al., Cardiovascular pre-participation screening of young competitive athletes for prevention of sudden death: proposal for a common European protocol. Consensus Statement of the Study Group of Sport Cardiology of the Working Group of Cardiac Rehabilitation and Exercise Physiology and the Working Group of Myocardial and Pericardial Diseases of the European Society of Cardiology, Eur Heart J, 26 (2005) 516-524.

[14] D. Corrado, A. Pelliccia, H. Heidbuchel, et al., Recommendations for interpretation of 12-lead electrocardiogram in the athlete, Eur Heart J, 31 (2010) 243-259. 
[15] J.A. Drezner, M.J. Ackerman, J. Anderson, et al., Electrocardiographic interpretation in athletes: the 'Seattle criteria', Br J Sports Med, 47 (2013) 122-124.

[16] B. Remenyi, N. Wilson, A. Steer, et al., World Heart Federation criteria for echocardiographic diagnosis of rheumatic heart disease--an evidence-based guideline, Nat Rev Cardiol, 9 (2012) 297-309.

[17] C.M. Fuller, C.M. McNulty, D.A. Spring, et al., Prospective screening of 5,615 high school athletes for risk of sudden cardiac death, Med Sci Sports Exerc, 29 (1997) 11311138 .

[18] B.J. Maron, P.D. Thompson, M.J. Ackerman, et al., Recommendations and considerations related to preparticipation screening for cardiovascular abnormalities in competitive athletes: 2007 update: a scientific statement from the American Heart Association Council on Nutrition, Physical Activity, and Metabolism: endorsed by the American College of Cardiology Foundation, Circulation, 115 (2007) 1643-1455.

[19] D. Corrado, C. Schmied, C. Basso, et al., Risk of sports: do we need a preparticipation screening for competitive and leisure athletes?, Eur Heart J, 32 (2011) 934944.

[20] J.A. Drezner, J. Fudge, K.G. Harmon, et al., Warning symptoms and family history in children and young adults with sudden cardiac arrest, J Am Board Fam Med, 25 (2012) 408-415.

[21] M.G. Wilson, F. Carre, O. Salah, et al., Significance of deep T-wave inversions in an asymptomatic athlete with a family history of sudden death: addendum--full sporting disqualification, Clin J Sport Med, 22 (2012) 284-287.

[22] M. Papadakis, F. Carre, G. Kervio, et al., The prevalence, distribution, and clinical outcomes of electrocardiographic repolarization patterns in male athletes of African/AfroCaribbean origin, Eur Heart J, 32 (2011) 2304-2313.

[23] M. Papadakis, S. Basavarajaiah, J. Rawlins, et al., Prevalence and significance of Twave inversions in predominantly Caucasian adolescent athletes, Eur Heart J, 30 (2009) 1728-1735.

[24] D. Corrado, C. Calore, A. Zorzi, et al., Improving the interpretation of the athlete's electrocardiogram, Eur Heart J, 34 (2013) 3606-3609.

[25] S. Gati, N. Sheikh, S. Ghani, et al., Should axis deviation or atrial enlargement be categorised as abnormal in young athletes? The athlete's electrocardiogram: time for reappraisal of markers of pathology, Eur Heart J, 34 (2013) 3641-3648.

[26] F. Schnell, N. Riding, R. O'Hanlon, et al., Recognition and significance of pathological T-wave inversions in athletes, Circulation, 131 (2015) 165-173.

[27] M. Mirabel, T. Fauchier, R. Bacquelin, et al., Echocardiography screening to detect rheumatic heart disease: A cohort study of schoolchildren in French Pacific Islands, Int J Cardiol, 188 (2015) 89-95.

[28] E. Marijon, M. Mirabel, D.S. Celermajer, et al., Rheumatic heart disease, Lancet, 379 (2012) 953-964.

[29] A. Magalski, B.J. Maron, M.L. Main, et al., Relation of race to electrocardiographic patterns in elite American football players, J Am Coll Cardiol, 51 (2008) 2250-2255.

[30] K.G. Harmon, I.M. Asif, D. Klossner, et al., Incidence of sudden cardiac death in National Collegiate Athletic Association athletes, Circulation, 123 (2011) 1594-1600.

[31] K.G. Harmon, J.A. Drezner, M.G. Wilson, et al., Incidence of sudden cardiac death in athletes: a state-of-the-art review, Br J Sports Med, 48 (2014) 1185-1192. 


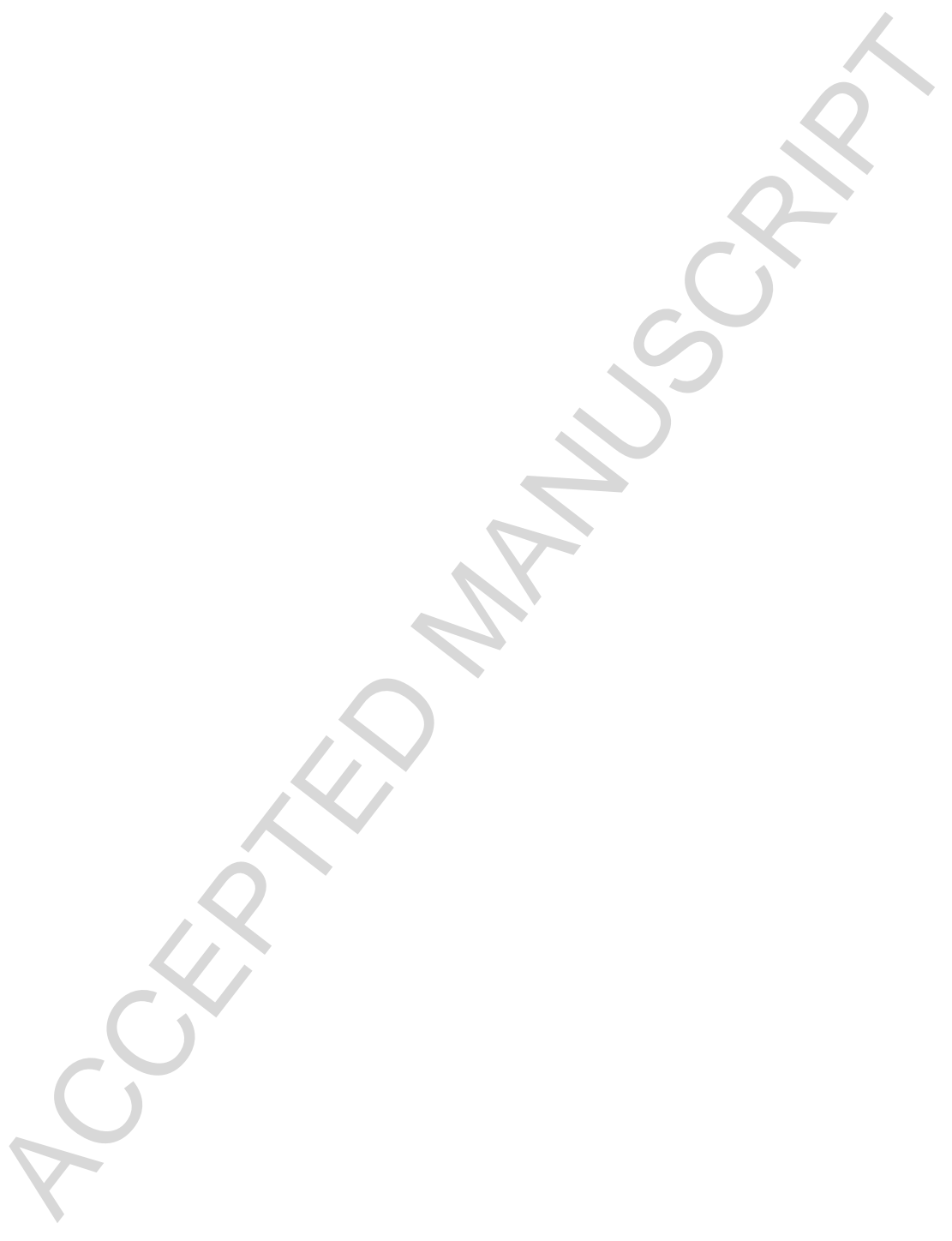




\section{Figures legend}

Figure 1: Number $(\%)$ of diagnosis elements found in the 88 cardiovascular (CV) abnormalities of the 2281 studied athletes after questionnaire concerning family history, personal history, symptoms and physical examination and after ECG and complementary investigations. CVD: cardiovascular disease.

Figure 2: Cardiovascular abnormalities, $n=88$, with sudden cardiac death risk, $n=18,(\mathbf{A})$, without any sudden cardiac death risk, $n=53,(\mathbf{B})$, with isolated abnormal ECG, $n=17$, (C). QT : Prolonged QT; CV mal: cardiovascular malformation; Inter AV: inter atrioventricular communication.

Figure 3: ECG of the 3 athletes that died of a sudden cardiac death. (A) was a Caucasian male triathlete with normal ECG. He died during a swimming session. (B) was a female Polynesian who died at rest. ECG was normal. The diagnosis of prolonged QT was suspected because her untrained sister presented a prolonged QTc $>480 \mathrm{~ms}$. (C) was an 18 year old male Melanesian football player diagnosed with HCM that died during a football match. 
Table 1 . Mean \pm SD characteristics of the 1565 males in relation to ethnicity and training level.

\begin{tabular}{|c|c|c|c|c|c|c|c|}
\hline Ethnicity & $\begin{array}{c}\text { Melanesians } \\
\mathrm{n}=424\end{array}$ & $\begin{array}{c}\text { Polynesians } \\
\mathrm{n}=488\end{array}$ & $\begin{array}{c}\text { Caucasians } \\
\mathrm{n}=331\end{array}$ & $\begin{array}{c}\text { Métis } \\
\mathrm{n}=322\end{array}$ & $\begin{array}{c}\mathrm{LT} \\
\mathrm{n}=592\end{array}$ & $\begin{array}{c}\text { HT } \\
n=973\end{array}$ & $\begin{array}{c}\text { Total } \\
\mathrm{n}=1565\end{array}$ \\
\hline Training $(\mathrm{h} / \mathrm{w})$ & 8.6 & $9.2^{\mathrm{f}}$ & $9.0^{\mathrm{h}}$ & 8.2 & $4.8^{*}$ & 11.2 & $8.8^{\bullet}$ \\
\hline $\mathrm{SD}$ & 5.7 & 6.0 & 4.0 & 3.4 & 1.2 & 5.0 & 5.1 \\
\hline Age (years) & $18.9^{\mathrm{a}}$ & $21.0^{\mathrm{g}}$ & 19.4 & 19.5 & $19.3^{*}$ & 20.1 & $19.8^{\bullet}$ \\
\hline SD & 6.6 & 5.6 & 7.1 & 6.4 & 6.7 & 6.3 & 6.4 \\
\hline Height $(\mathrm{cm})$ & $168.3^{\mathrm{ad}}$ & $179.8^{g}$ & $173.1^{\mathrm{h}}$ & 174.7 & $172.5^{*}$ & 175.3 & $174^{\circ}$ \\
\hline $\mathrm{SD}$ & 14.2 & 8.1 & 11.6 & 11.5 & 13.1 & 11.6 & 12 \\
\hline Weight (kg) & $66.7^{\mathrm{ad}}$ & $82.0^{\mathrm{g}}$ & $65.1^{h}$ & 72.2 & $71.0 *$ & 73.0 & $72^{\circ}$ \\
\hline SD & 20.7 & 16.5 & 16.1 & 18.4 & 20.4 & 18.6 & 19 \\
\hline HR (bpm) & $66.3^{d}$ & $66.2^{\mathrm{g}}$ & 62.4 & 63.0 & $67.4^{*}$ & 63.2 & $64.8^{\circ}$ \\
\hline SD & 12.4 & 11.5 & 11.8 & 11.4 & 12.3 & 11.3 & 11.9 \\
\hline PR (ms) & $152^{\mathrm{a}}$ & $156^{\mathrm{g}}$ & $147^{\mathrm{h}}$ & 152 & $150 *$ & 154 & $152^{\circ}$ \\
\hline $\mathrm{SD}$ & 23 & 22 & 22 & 25 & 23 & 23 & 23 \\
\hline LAE (\%) & $2.8^{a b}$ & $0.2^{\mathrm{g}}$ & $4.5^{\mathrm{h}}$ & 3.1 & 3.0 & 2.1 & $2.4^{\circ}$ \\
\hline RAE (\%) & 0.2 & 0.6 & 0.6 & 0.6 & $0.2 *$ & 0.7 & $0.5^{\circ}$ \\
\hline QRS (ms) & $96^{\mathrm{ac}}$ & 98 & 97 & 98 & $95^{*}$ & 98 & $97^{\bullet}$ \\
\hline $\mathrm{SD}$ & 12 & 11 & 12 & 11 & 12 & 11 & 11 \\
\hline LVH (\%) & $15.6^{\mathrm{ab}}$ & $19.9^{\mathrm{g}}$ & 25.1 & 17.1 & $15.2 *$ & 21.7 & $19.2^{\circ}$ \\
\hline RVH (\%) & $5.4^{\text {ad }}$ & $13.9^{\mathrm{g}}$ & 7.9 & 8.1 & $7.3^{*}$ & 10.3 & $9.1^{\bullet}$ \\
\hline IRBBB \% & $56.4^{\mathrm{a}}$ & $45.9^{\mathrm{g}}$ & 67.4 & 60.9 & 54.7 & 57.3 & $56.4^{\circ}$ \\
\hline CRBBB (\%) & 0.2 & 0.2 & 0.3 & 0.6 & 0.2 & 0.4 & $0.3^{\bullet}$ \\
\hline ILBBB (\%) & 0.7 & 1.2 & 0.6 & 1.2 & 1.2 & 0.8 & $11.0^{\circ}$ \\
\hline $\mathrm{ERP} \geq 2 \%$ & 60.6 & 63.7 & 58.6 & 65.5 & $56.4 *$ & 65.7 & $62.2^{\circ}$ \\
\hline TWI (\%) & $2.6^{\mathrm{ad}}$ & 1.2 & 1.5 & 1.2 & $1.5^{*}$ & 2.1 & $1.9^{\circ}$ \\
\hline QTc (ms) & $413^{d}$ & $413^{g}$ & 407 & 409 & 411 & 410 & $411^{\circ}$ \\
\hline $\mathrm{SD}$ & 22 & 23 & 23 & 23 & 22 & 23 & 23 \\
\hline
\end{tabular}


Training (h/w): duration of training (hour/week), HR: heart rate, LAE: left atrial enlargement, RAE: right atrial enlargement, LVH: left ventricular hypertrophy, RVH: right ventricular hypertrophy, I/C/R/LBBB: incomplete/complete/right/left bundle branch block, ERP: early repolarization, TWI: T wave inversion, LT: low, HT: high training level.

SD standard deviation; $P<0.05$

${ }^{\mathrm{a}}$ Melanesians vs. Polynesians; ${ }^{\mathrm{b}}$ Melanesians vs. Caucasians; ${ }^{\mathrm{c}}$ Melanesians vs. Métis

${ }^{\mathrm{d}}$ Melanesians vs. Caucasians and Métis; ${ }^{\mathrm{e}}$ Polynesian vs. Caucasian; ${ }^{\mathrm{f}}$ Polynesian vs. Métis

${ }^{\mathrm{g}}$ Polynesian vs. Caucasian and Métis; ${ }^{\mathrm{h}}$ Caucasian vs. Métis;

* LT vs. HT; ${ }^{\bullet}$ males vs. females see table $1 \mathrm{~b}$ 
Table 2. Mean \pm SD characteristics of the 716 females in relation to ethnicity and training level.

\begin{tabular}{|c|c|c|c|c|c|c|c|}
\hline Ethnicity & $\begin{array}{c}\text { Melanesians } \\
\mathrm{n}=278\end{array}$ & $\begin{array}{c}\text { Polynesians } \\
n=165\end{array}$ & $\begin{array}{c}\text { Caucasians } \\
\mathrm{n}=138\end{array}$ & $\begin{array}{l}\text { Métis } \\
\mathrm{n}=135\end{array}$ & $\begin{array}{c}\mathrm{LT} \\
\mathrm{n}=353\end{array}$ & $\begin{array}{c}\text { HT } \\
n=363\end{array}$ & $\begin{array}{c}\text { Total } \\
n=716\end{array}$ \\
\hline Training (h/w) & $7.6^{\mathrm{a}}$ & 9.4 & 7.9 & 8.4 & $4.6^{*}$ & 11.7 & $8.2^{\circ}$ \\
\hline $\mathrm{SD}$ & 5.3 & 5.4 & 3.5 & 4.5 & 1.3 & 4.6 & 4.9 \\
\hline Age (years) & $17.7^{\mathrm{ac}}$ & 19.7 & 18.0 & 19.3 & $17.5^{*}$ & 19.6 & $18.6^{\circ}$ \\
\hline SD & 6.4 & 6.2 & 6.4 & 7.0 & 6.3 & 6.6 & 6.5 \\
\hline Height $(\mathrm{cm})$ & $161.0^{\mathrm{ac}}$ & $170.5^{\mathrm{g}}$ & 164.3 & 166.5 & $163^{*}$ & 167 & $165^{\circ}$ \\
\hline SD & 9.6 & 7.7 & 8.6 & 8.1 & 9.4 & 9.0 & 9.5 \\
\hline Weight (kg) & $59.0^{\mathrm{ac}}$ & $70.2^{g}$ & $57.0^{h}$ & 61.8 & $60 *$ & 64 & $62^{\circ}$ \\
\hline $\mathrm{SD}$ & 14.2 & 14.3 & 12.6 & 12.1 & 14.8 & 13.6 & 14.4 \\
\hline HR (bpm) & $71.0^{\mathrm{ad}}$ & 67.0 & 66.7 & 67.7 & $70 *$ & 67 & $69^{\circ}$ \\
\hline SD & 14.1 & 12.5 & 12.8 & 12.4 & 13.7 & 12.8 & 13.3 \\
\hline PR (ms) & $144^{\mathrm{a}}$ & $150^{\mathrm{e}}$ & $141^{\mathrm{h}}$ & 147 & $143 *$ & 147 & $145^{\circ}$ \\
\hline $\mathrm{SD}$ & 21 & 21 & 20 & 20 & 22 & 20 & 21 \\
\hline LAE (\%) & $1.8^{\mathrm{ad}}$ & $0.6^{\mathrm{e}}$ & $4.3^{\mathrm{h}}$ & 0.7 & $2.3 *$ & 1.4 & $1.8^{\circ}$ \\
\hline RAE (\%) & 0 & 2.4 & 0.7 & 0.7 & $0.6 *$ & 1.2 & $0.8^{\bullet}$ \\
\hline QRS (ms) & 89 & 89 & 89 & 90 & $88^{*}$ & 90 & $89^{\circ}$ \\
\hline SD & 9 & 11 & 11 & 11 & 9.2 & 10.6 & 9.9 \\
\hline LVH (\%) & $3.2^{\mathrm{ab}}$ & $4.2^{\mathrm{e}}$ & 1.4 & 3.7 & $2.3 *$ & 4.1 & $3.2^{\circ}$ \\
\hline $\mathrm{RVH}(\%)$ & $2.5^{\mathrm{a}}$ & $6.7^{\mathrm{g}}$ & 2.9 & 2.2 & $3.1 *$ & 3.9 & $3.5^{\circ}$ \\
\hline IRBBB \% & $37.8^{\mathrm{ad}}$ & $27.9^{g}$ & 52.2 & 48.1 & 39.9 & 40.5 & $40.2^{\circ}$ \\
\hline CRBBB (\%) & 0 & 0 & 0.7 & 0 & 0 & 0.3 & $0.1^{\bullet}$ \\
\hline ILBBB (\%) & 0 & 0 & 0.7 & 0 & 0 & 0.3 & $0.1^{\bullet}$ \\
\hline $\mathrm{ERP} \geq 2 \%$ & $12.6^{\mathrm{ad}}$ & $9.7^{\mathrm{g}}$ & $14.3^{h}$ & 13.3 & $9.3 *$ & 15.4 & $12.4^{\circ}$ \\
\hline TWI (\%) & $3.6^{\mathrm{ad}}$ & $1.2^{\mathrm{e}}$ & $2.2^{\mathrm{h}}$ & 0.7 & $2.8^{*}$ & 1.7 & $2.2^{\circ}$ \\
\hline QTc $(\mathrm{ms})$ & $422^{b}$ & $425^{\mathrm{e}}$ & $416^{h}$ & 422 & 421 & 423 & $422^{\circ}$ \\
\hline SD & 21 & 24 & 22 & 25 & 22 & 25 & 23 \\
\hline
\end{tabular}


Training (h/w): duration of training (hour/week), HR: heart rate, LAE: left atrial enlargement, RAE: right atrial enlargement, LVH: left ventricular hypertrophy, RVH: right ventricular hypertrophy, I/C/R/LBBB: incomplete/complete/right/left bundle branch block, ERP: early repolarization, TWI: T wave inversion, LT: low, HT: high training level.

SD standard deviation; $P<0.05$

${ }^{\mathrm{a}}$ Melanesians vs. Polynesians; ${ }^{\mathrm{b}}$ Melanesians vs. Caucasians; ${ }^{\mathrm{c}}$ Melanesians vs. Métis

${ }^{\mathrm{d}}$ Melanesians vs. Caucasians and Métis s; ${ }^{\mathrm{e}}$ Polynesian vs. Caucasian; ${ }^{\mathrm{f}}$ Polynesian vs. Métis

${ }^{\mathrm{g}}$ Polynesian vs. Caucasian and Métis; ${ }^{\mathrm{h}}$ Caucasian vs. Métis.

*LT vs. HT; 'males vs. females see table 1a 
Table 3. Number (\%) of cardiovascular (CV) abnormalities (1) with risk of sudden cardiac death (SCD), (2) without any risk of SCD, (3) isolated abnormal ECGs without any diagnosis and (4) number of SCDs over the 5-year study period in the 2281 athletes grouped by ethnicity, gender and training level.

\begin{tabular}{|c|c|c|c|c|c|c|c|c|c|c|}
\hline & $\begin{array}{l}\text { Ethnicity } \\
\mathrm{n}\end{array}$ & $\begin{array}{c}\text { Melanesians } \\
702\end{array}$ & $\begin{array}{c}\text { Polynesians } \\
653\end{array}$ & $\begin{array}{c}\text { Caucasians } \\
469\end{array}$ & $\begin{array}{l}\text { Métis } \\
457\end{array}$ & $\begin{array}{l}\text { Males } \\
1565\end{array}$ & $\begin{array}{c}\text { Females } \\
716\end{array}$ & $\begin{array}{l}\text { LT } \\
945\end{array}$ & $\begin{array}{c}\mathrm{HT} \\
1336\end{array}$ & $\begin{array}{l}\text { Total } \\
2281\end{array}$ \\
\hline \multirow{5}{*}{$\begin{array}{l}(1) \\
18 \mathrm{CV} \\
\text { abnormalities } \\
\text { with SCD } \\
\text { risk }\end{array}$} & $\mathrm{CM}$ & 2 & 3 & 0 & 1 & 6 & 0 & 1 & 5 & 6 \\
\hline & WPW & 2 & 4 & 0 & 0 & 5 & 1 & 2 & 4 & 6 \\
\hline & S. Val. lesion & 0 & 3 & 1 & 1 & 4 & 1 & 0 & 5 & 5 \\
\hline & Prolonged QT & 0 & 1 & 0 & 0 & 1 & 0 & 0 & 1 & 1 \\
\hline & Sub-total $(\%)$ & $4(0.6)^{\mathrm{a}}$ & $11(1.7)^{\mathrm{g}}$ & $1(0.2)$ & $2(0.4)$ & $16(1.0)$ & $2(0.3)^{\bullet}$ & $3(0.3)^{*}$ & $15(1.1)$ & $18(0.8)$ \\
\hline \multirow{6}{*}{$\begin{array}{l}\text { (2) } \\
53 \mathrm{CV} \\
\text { abnormalities } \\
\text { with regular } \\
\text { follow up }\end{array}$} & Other valve lesion & 11 & 6 & 8 & 5 & 20 & 10 & 14 & 16 & 30 \\
\hline & Inter AV com. & 4 & 0 & 3 & 1 & 5 & 3 & 5 & 3 & 8 \\
\hline & Arrhythmia & 1 & 4 & 1 & 2 & 6 & 2 & 4 & 4 & 8 \\
\hline & HBP & 0 & 5 & 0 & 1 & 6 & 0 & 1 & 5 & 6 \\
\hline & CVM & 0 & 0 & 1 & 0 & 0 & 1 & 0 & 1 & 1 \\
\hline & Sub-total (\%) & $16(2.3)^{b}$ & $15(2.3)^{\mathrm{ef}}$ & $13(2.8)$ & $9(2.0)$ & $37(2.4)$ & $16(2.2)$ & $24(2.5)^{*}$ & $29(2.2)$ & $53(2.3)$ \\
\hline$(1)+(2)$ & Total $(\%)$ & $20(2.8)^{\mathrm{ac}}$ & $26(4.0)^{\mathrm{g}}$ & $14(3.0)^{\mathrm{h}}$ & $11(2.4)$ & $52(3.3)^{\bullet}$ & $18(2.5)$ & $27(2.9)$ & $43(3.2)$ & $71(3.1)$ \\
\hline \multirow{5}{*}{$\begin{array}{l}\text { (3) } \\
17 \text { isolated } \\
\text { abnormal ECG }\end{array}$} & T wave inversion & 3 & 5 & 2 & 0 & 8 & 2 & 7 & 3 & 10 \\
\hline & Prolonged QT & 1 & 2 & 0 & 1 & 2 & 2 & 2 & 2 & 4 \\
\hline & CM suspicion & 0 & 0 & 0 & 2 & 2 & 0 & 0 & 2 & 2 \\
\hline & Q wave & 0 & 1 & 0 & 0 & 1 & 0 & 0 & 1 & 1 \\
\hline & Sub-total $(\%)$ & $4(0.6)^{b}$ & $7(1.1)^{\mathrm{e}}$ & $2(0.4)^{\mathrm{h}}$ & $4(0.9)$ & $14(0.9)$ & $3(0.4)$ & $9(1.0)^{*}$ & $8(0.6)$ & $17(0.7)$ \\
\hline$(1)+(2)+(3)$ & Total $(\%)$ & $24(3.4)^{\mathrm{a}}$ & $33(5.1)^{\mathrm{g}}$ & $16(3.4)$ & $15(3.3)$ & $66(4.2)^{\bullet}$ & $22(3.1)$ & $36(3.8)$ & $52(3.9)$ & $88(3.9)$ \\
\hline (4) SCD over 5yrs & & 1 & 1 & 1 & 0 & 2 & 1 & 0 & 3 & 3 \\
\hline
\end{tabular}

CM: cardiomyopathy, WPW: Wolff-Parkinson-White, S. Val.: Severe valve, Vent: ventricular, Inter AV com: inter atrial or ventricular communication, HBP : high blood pressure, CVM: cardio vascular malformation, R: Right. LT, HT: low and high level of training, $P<0.05$ 
${ }^{\mathrm{a}}$ Melanesians vs. Polynesians; ${ }^{\mathrm{b}}$ Melanesians vs. Caucasians; ${ }^{\mathrm{c}}$ Melanesians vs. Métis

${ }^{\mathrm{d}}$ Melanesians vs. Caucasians and Métis; ${ }^{\mathrm{e}}$ Polynesian vs. Caucasian; ${ }^{\mathrm{f}}$ Polynesian vs. Métis; ${ }^{\mathrm{g}}$ Polynesian vs. Caucasian and Métis

${ }^{\mathrm{h}}$ Caucasian vs. Métis; *LT vs. HT; ${ }^{\circ}$ males vs. females 


\section{Highlights : What are the new findings?}

- This study provides new information on the prevalence of cardiovascular disease and abnormalities in male and female Melanesians, Polynesians, Caucasians and Métis Pacific Island athletes and in low and highly trained athletes.

Melanesians had a higher rate of $\mathrm{T}$ waves inversion in V2-V4 than others and were similar to those in Afro-Caribbean athletes.

The prevalence of valvular diseases of rheumatoid origin was clearly higher than in Western and Middle East countries. 


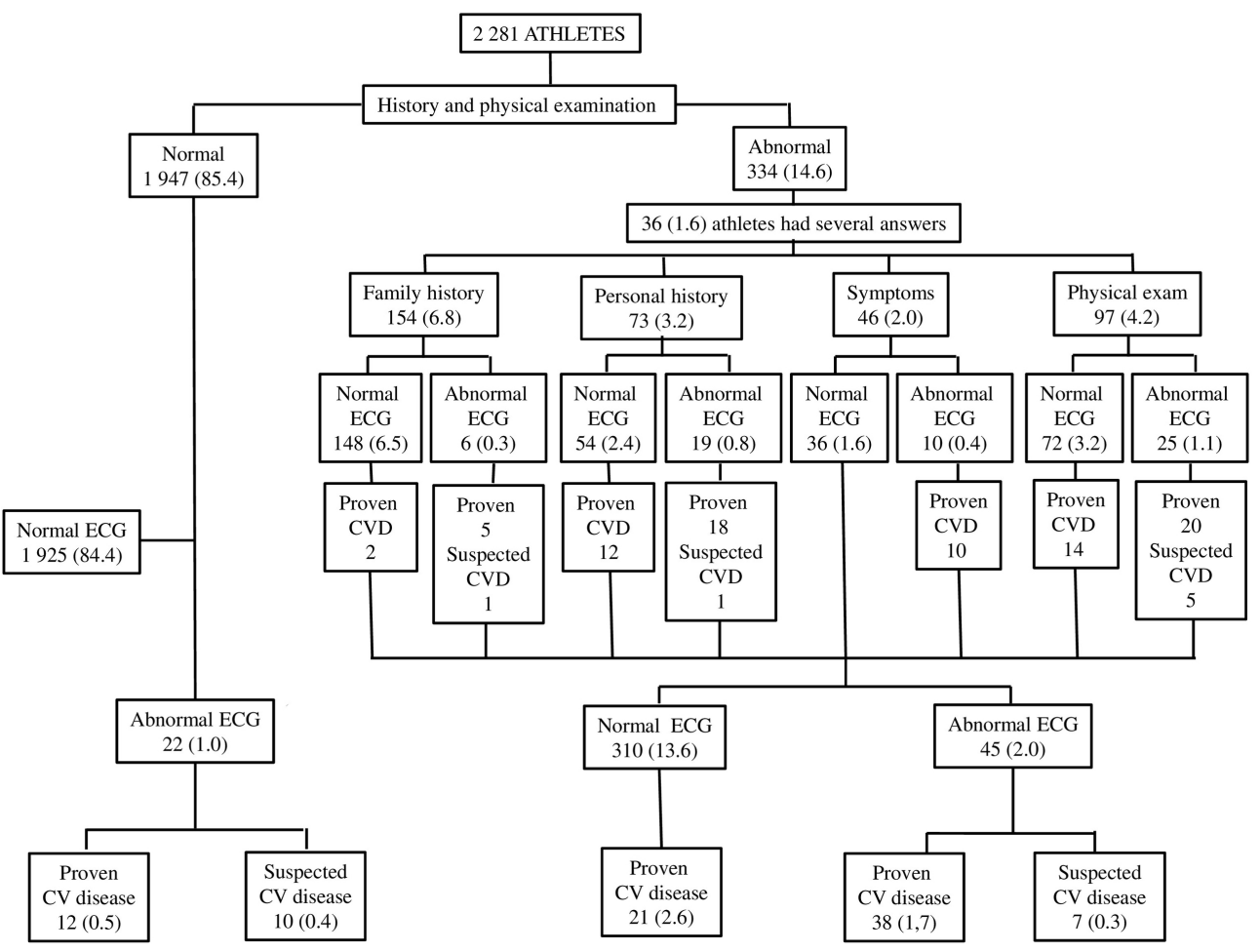

Figure 1 


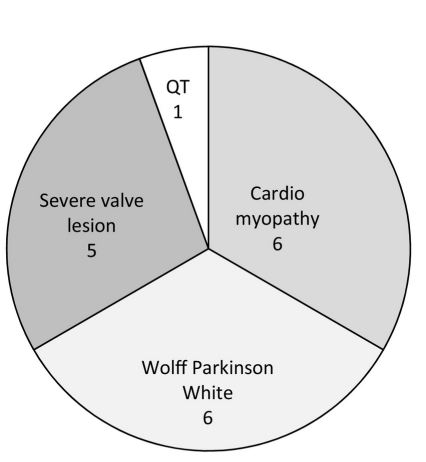

A

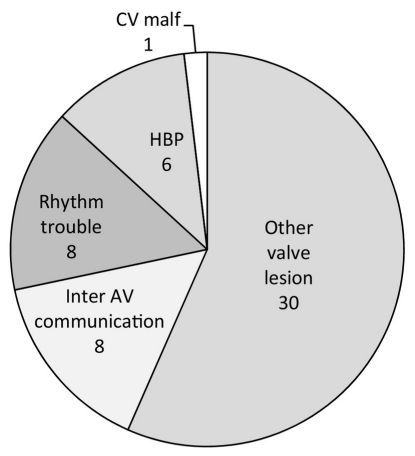

B

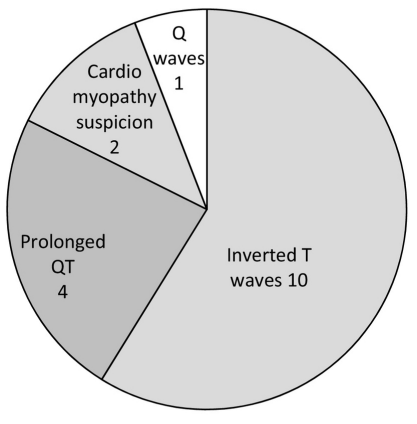

C

Figure 2 


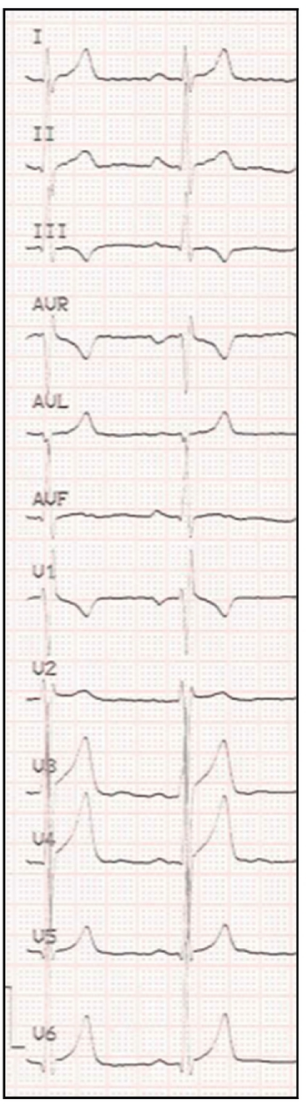

A
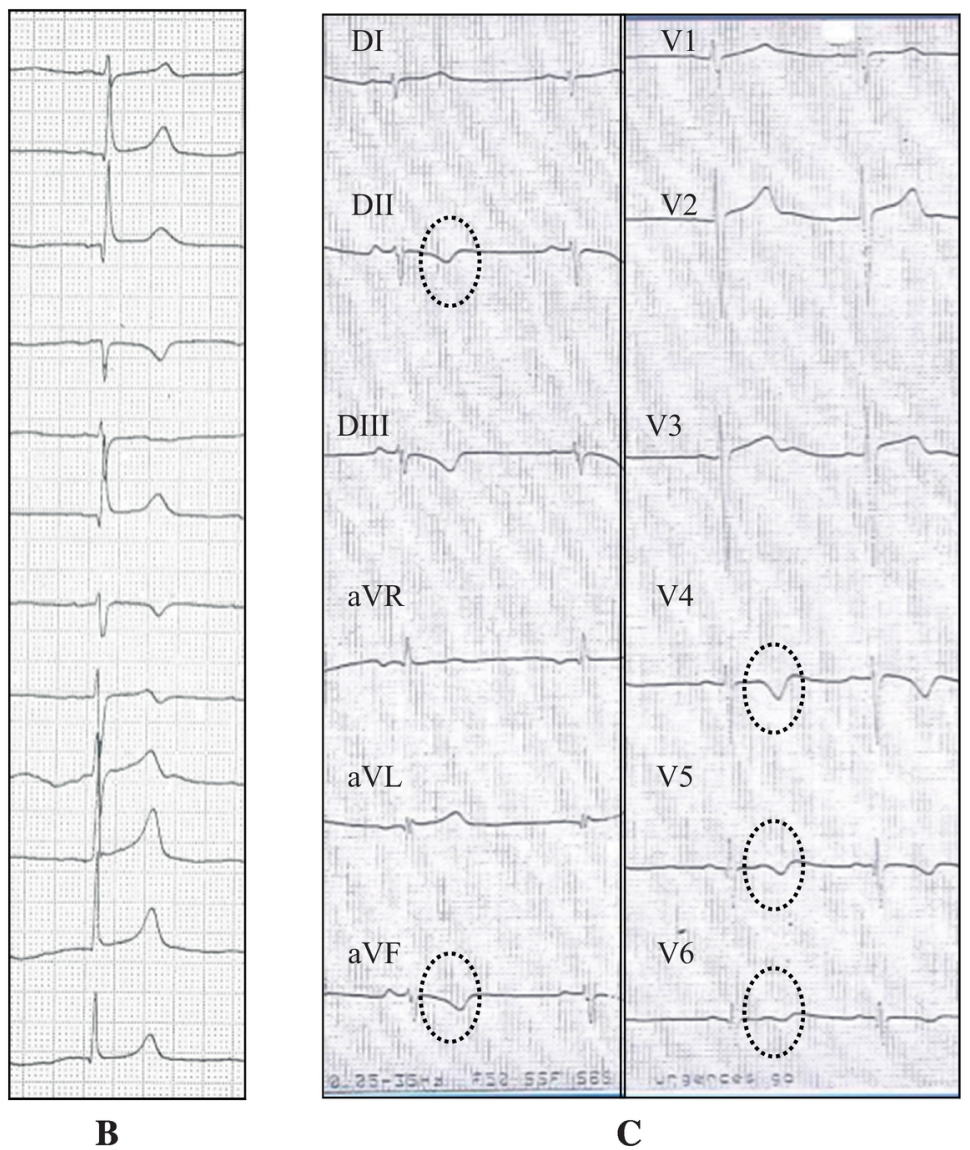

Figure 3 